\title{
Pituitary Apoplexy, Meningitis and Cerebral Infarction - A Perplexing Trifecta
}

\section{Apoplexia hipofisária, meningite e infarto cerebral - um trifecta desconcertante}

\author{
Thirumalai V. Srivatsan ${ }^{1}$ Haroon M. Pillay ${ }^{1}$ Lakshay Raheja1] \\ ${ }^{1}$ Department of Neurosurgery, Medical Trust Hospital, Kochi, Kerala, \\ India \\ Address for correspondence Thirumalai V. Srivatsan, MBBS, DNB, \\ Department of Neurosurgery, Medical Trust Hospital, Kochi, Kerala, \\ India (e-mail: drtvsrivatsan@gmail.com).
} Arq Bras Neurocir 2021;40(4):e364-e367.

\begin{abstract}
Pituitary apoplexy (PA) is a clinical diagnosis comprising a sudden onset of headache, neurological deficits, endocrine disturbances, altered consciousness, visual loss, or ophthalmoplegia. However, clinically, the presentation of PA is extremely variable and

Keywords

- pituitary apoplexy

- stroke

- cerebral infarct

- meningitis

\section{Resumo}

\section{Palavras-chave}

- apoplexia pituitária

- derrame

- enfarte cerebral

- meningite occasionally fatal. While meningitis and cerebral infarcts are themselves serious diseases, they are rarely seen as manifestations of PA and are exceedingly rare when present together.

We present the case of a 20-year-old male with a rapid progression of symptoms of meningitis, PA and stroke. The present article seeks to emphasize a rare manifestation of $P A$ with an attempt to understand the intricacies of its evaluation and management.

A apoplexia hipofisária (AP) é um diagnóstico clínico que compreende um início súbito de dor de cabeça, déficits neurológicos, distúrbios endócrinos, alteração da consciência, perda de visão ou oftalmoplegia. No entanto, clinicamente, a apresentação de PA é extremamente variável e ocasionalmente fatal. Embora a meningite e os infartos cerebrais sejam eles próprios graves doenças, eles raramente são vistos como manifestações de PA e são extremamente raros quando presentes juntos.

Apresentamos o caso de um homem de 20 anos com uma rápida progressão dos sintomas de meningite, PA e acidente vascular cerebral. O presente artigo busca enfatizar uma manifestação rara. da AP na tentativa de compreender as complexidades de sua avaliação e manejo.
\end{abstract}

\section{Introduction}

Pituitary apoplexy (PA) is a clinical diagnosis comprising a sudden onset of headache, neurological deficits, endocrine disturbances, altered consciousness, visual loss, or ophthalmoplegia. ${ }^{1}$ It is often characterized by infarction and/or

received

December 11, 2020

accepted

DOI https://doi.org/

10.1055/s-0041-1733947.

ISSN $0103-5355$.

June 16, 2021

published online

August 3, 2021 hemorrhage within a pituitary tumor, usually a macroadenoma, followed by a sudden expansion and subsequent compression of surrounding structures. ${ }^{2}$

However, PA is known to have a protean manifestation and can be difficult to diagnose. ${ }^{1}$ Meningitis and cerebral infarcts are by themselves serious diseases. They are rarely

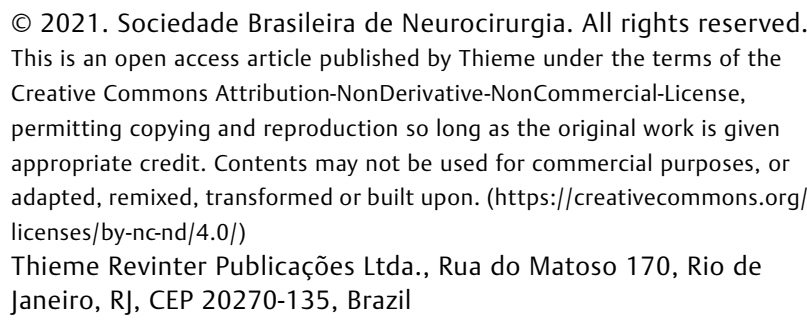


seen as separate manifestations of PA, with only one case report describing both occurring simultaneously. ${ }^{3}$ When meningitis and cerebral infarcts occur with PA, they significantly complicate the disease progression and its management. The management of PA is not standardized and consists of conservative management with intravenous fluids and steroids, and judiciously chosen trans-sphenoidal surgery. ${ }^{1,2}$ As it is often a medical emergency, identifying PA and managing it adequately to prevent its complications is paramount. $^{2}$

\section{Case Report}

Patient data was collected after obtaining patient consent and Institutional Ethics Committee clearance. A 20-year-old male presented with complaints of acute onset headache for 2 days, which was progressively worsening and was associated with vomiting and 1 day history of fever. He was conscious and alert with no neurological deficits but had mild neck rigidity. A working diagnosis of meningitis was reached, and a guarded lumbar puncture (LP) was performed. Cerebrospinal fluid (CSF) studies showed gramnegative bacilli, glucose $32 \mathrm{mg} / \mathrm{dl}$, protein $636 \mathrm{mg} / \mathrm{dl}$, total count of 400 cells $/ \mathrm{mm}^{3}$ ( $80 \%$ polymorphs). He was started on empirical antibiotics and a CSF culture was ordered.

Within a few hours, his headache worsened and was followed by the development of bitemporal hemianopia, bilateral papilledema, and right lateral rectus palsy. Magnetic resonance imaging (MRI) demonstrated a large pituitary macroadenoma $(3.5 \times 2 \times 2.5 \mathrm{~cm}$ ) with regions of hemorrhage ( - Fig. 1 ), and a diagnosis of PA was reached. The endocrinological evaluation was significant only for raised levels of growth hormone, at $8.07 \mathrm{ng} / \mathrm{ml}(0.15-5.0 \mathrm{ng} / \mathrm{ml})$. The 8 Am serum cortisol level was 3 $\mathrm{mcg} / \mathrm{dl}$ (5-25mcg/dl). As the patient was neurologically stable, conservative management was opted for, and he was started on hydrocortisone.

On the $2^{\text {nd }}$ day of admission, he suddenly deteriorated, becoming obtunded, and developed left hemiplegia. An urgent MRI with MR angiogram (MRA) revealed enlarged areas of hemorrhage and infarct within the tumor, with an overall mild increase in the size of the tumor. Large areas of

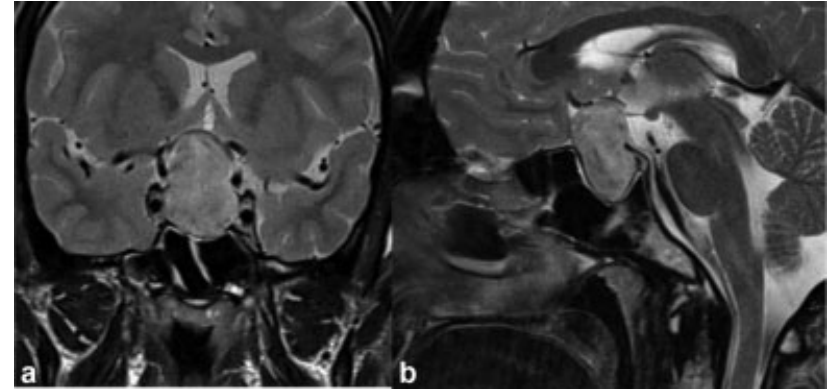

Fig. 1 T2W MRI with (a) coronal image (b) saggital image showing heterogenous intensity sellar-suprasellar tumor displacing the optic chiasm and anterior cerebral arteries bilaterally, right more than left.

infarct were noted over the bilateral basifrontal regions extending to the right internal capsule and the basal ganglia. The anterior communicating arteries were noted to be splayed over the tumor with a mild decrease in diameter. (-Fig. 2) As the patient continued to have fever; surgical decompression was planned but was deferred due to higher risks.

Over the next few days, he was stable, and his consciousness improved; however, the CSF culture did not show any growth. Hence, a repeat LP was performed, and CSF cultures were sent again along with a meningitis syndrome evaluation system test (Xcyton SES panel, Bangalore, India), which also did not show any offending organism. During this period, he developed diabetes insipidus, which was managed conservatively.

On the $6^{\text {th }}$ day postadmission, his vision abruptly deteriorated, with loss of perception of light in the right eye, and with the left eye only detecting hand movements. A rapid decline in vision, along with remission in fever, prompted an endoscopic transsphenoidal pituitary tumor excision. Following surgery, he regained the ability to perceive light in the right eye and was able to walk with support at the end of 3 months. A postoperative MRI revealed that the tumor was completely excised and the patient was started on hydrocortisone for postoperative hypopituitarism.

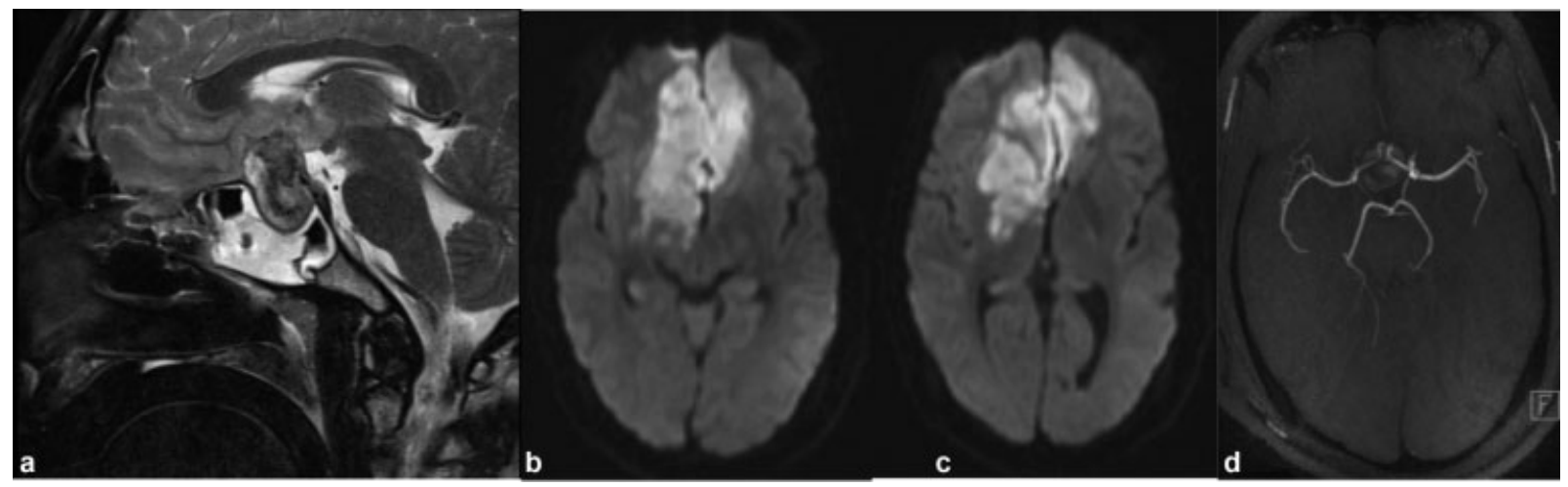

Fig. 2 (a) T2W MRI saggital image showing altered intensity of the tumor suggestive of an intratumoral bleed; (b) and (c) MRI DWI images showing diffusion restriction in basal bilateral anterior lobes extending to the right putamen, lenticular nucleus and internal capsule; (d) MRA showing narrowing of the anterior cerebral arteries, right more than left. 


\section{Discussion}

Pituitary apoplexy is known to present with chemical meningitis and, rarely, may present concurrently with bacterial meningitis, which itself has been suspected to precipitate PA. ${ }^{4-9}$ Pituitary apoplexy has, infrequently, even been misdiagnosed as bacterial meningitis ${ }^{7,8}$ due to a very similar clinical picture. Cerebrospinal fluid findings such as pleocytosis and erythrocytosis are nonspecific in cases of PA with suspected meningitis, with demonstration of bacteria in CSF being a key finding in distinguishing between chemical and pyogenic meningitis. ${ }^{4}$ Although the initial screening CSF studies showed gram-negative bacteria in our patient, the culture and meningitis polymerase chain reaction (PCR) panel did not show any causative organism. Traditional culture techniques are the gold standard for diagnosis, but may not always be reliable due to a relatively restricted sensitivity, ${ }^{10,11}$ and even polymerase chain-based tests such as the Xcyton SES panel may not have a $100 \%$ positive predictive value. $^{12}$ Given this, we decided that bacterial meningitis could not be ruled out completely, and empirical antibiotics were continued. Hydrocortisone was continued in view of the PA, as well as for meningitis. ${ }^{13}$

Cerebral infarction (without meningitis) associated with PA has been reported uncommonly. In a recent literature review of cerebral infarction associated with $\mathrm{PA}$, the pathogenesis was reported as being due to direct intracranial vascular compression or vasospasm, either separately or together. ${ }^{14}$ Mechanical compression was most commonly unilateral, but rarely bilateral. Vasospasm has been postulated as being due to vasoactive substances being released by the tumor itself or by the compressed hypothalamus, or due to subarachnoid hemorrhage (SAH) from the tumor. ${ }^{14}$ Cerebrovascular accident (CVA) in patients with bacterial meningitis is an important complication, often portending a poor prognosis, and its etiology is uncertain. Vasculitis, reversible vasospasm, embolism, and intra-arterial thrombosis have all been implicated as various causes. ${ }^{15}$ In our patient, we suspect that he developed infarcts secondary to vasospasm, affecting predominantly the anterior cerebral artery territory, as the MRA did not show any evidence of vasculitis or thromboembolism. The etiology of the vasospasm itself is uncertain and could be secondary to meningitis or PA in our patient. It may be reasonable, based on the rapid succession of symptoms of meningitis, later PA, and CVA, that these pathologies may be linked.

There is no universally accepted protocol for the management of cerebral infarction associated with PA. Antiplatelet therapy is the cornerstone of ischemic stroke management. However, in PA, unlike the standard treatment of ischemic stroke, antiplatelet therapy may aggravate or worsen the outcome, whereas surgical tumor decompression along with hormone replacement is thought to be associated with better outcomes. ${ }^{14}$ Hence, antiplatelet therapy was not considered for our patient in the acute phase. Nimodipine, which has some evidence for use in post-SAH vasospasm, has not shown benefit in stroke related to meningitis and was also not used in our patient. ${ }^{15}$
Surgery in our patient was delayed due to the risks associated with infection during the febrile phase as well as due to the acute CVA. Delayed rather than early surgery in PA with cerebral infarction is associated with better outcome, although infarction itself is not an indication for surgery. ${ }^{14,16}$ This may be due to the poorer outcome associated with the infarct itself in the immediate phase, and patients surviving long enough to undergo surgery may have better outcomes.

To the best of our knowledge, the simultaneous presentation of both meningitis and cerebral infarction in a single patient has been documented in only one report. Jeon et al. reported a case of a 41-year-old male presenting with pituitary apoplexy and chemical meningitis who developed left hemiparesis due to stroke 7 days later. ${ }^{3}$ In our patient, the sequence of events escalated within 48 hours, increasing the likelihood that the events were not disparate, but related phenomena, as has been suggested in the literature. $^{3}$

It is imperative to understand that the standard treatments related to cerebral infarcts may not be useful in these patients and may even exacerbate their conditions.

\section{Conclusion}

Concurrent meningitis and cerebral infarction aggravating the clinical course of PA, which is itself an often-fatal disease, is a rare clinical entity. Meningitis is difficult to diagnose in the setting of PA, as the CSF picture may be extremely similar. Adequate clinical suspicion must be maintained for its timely treatment. The present report seeks to emphasize the precarious nature of PA and the importance of its rapid diagnosis and management.

\section{Disclosure}

The authors certify that the present work is genuine, original, and has not submitted anywhere, either in part or in full. They also declare that they have no financial or nonfinancial competing interests.

\section{Conflict of Interests}

The authors have no conflict of interests to declare.

\section{References}

1 Pyrgelis ES, Mavridis I, Meliou M. Presenting Symptoms of Pituitary Apoplexy. J Neurol Surg A Cent Eur Neurosurg 2018;79(01): 52-59

2 Dubuisson AS, Beckers A, Stevenaert A. Classical pituitary tumour apoplexy: clinical features, management and outcomes in a series of 24 patients. Clin Neurol Neurosurg 2007;109(01):63-70

3 Jeon BC, Park YS, Oh HS, Kim YS, Chun BK. Pituitary apoplexy complicated by chemical meningitis and cerebral infarction. J Korean Med Sci 2007;22(06):1085-1089

4 Chu C, Perilli GA, Judge C, Sheng S, Yacoub HA. Pituitary apoplexy mimicking meningoencephalitis: case report and scoping study. Hosp Pract (1995) 2020;48(01):29-34. Doi: 10.1080/21548331. 2020.1717801

5 Hakeem H, Anwar SSM, Siddiqui SJ. Ischaemic pituitary tumour apoplexy and concurrent meningitis: a diagnostic dilemma. BMJ Case Rep 2017;2017:bcr2017221614 
6 Brouns R, Crols R, Engelborghs S, De Deyn PP. Pituitary apoplexy presenting as chemical meningitis. Lancet 2004;364(9433):502

7 Lakhdar F, Benzagmout M, Chakour K, Chaoui MF. Pituitary tumor apoplexy presenting as infective meningoencephalitis. Interdiscip Neurosurg 2019;18:100488

8 Wong SH, Das K, Javadpour M. Pituitary apoplexy initially mistaken for bacterial meningitis. BMJ Case Rep 2013;2013:bcr2013009223

9 Valente M, Marroni M, Stagni G, Floridi P, Perriello G, Santeusanio F. Acute sterile meningitis as a primary manifestation of pituitary apoplexy. J Endocrinol Invest 2003;26(08):754-757

10 Khater WS, Elabd SH. Identification of Common Bacterial Pathogens Causing Meningitis in Culture-Negative Cerebrospinal Fluid Samples Using Real-Time Polymerase Chain Reaction. Int J Microbiol 2016;2016:4197187

11 Brouwer MC, Tunkel AR, van de Beek D. Epidemiology, diagnosis, and antimicrobial treatment of acute bacterial meningitis. Clin Microbiol Rev 2010;23(03):467-492
12 Vetter P, Schibler M, Herrmann JL, Boutolleau D. Diagnostic challenges of central nervous system infection: extensive multiplex panels versus stepwise guided approach. Clin Microbiol Infect 2020;26(06):706-712. Doi: 10.1016/j.cmi.2019.12. 013

13 Brouwer MC, Mcintyre P, Prasad K, van de Beek D. Corticosteroids for acute bacterial meningitis. Vol. 2016, Cochrane Database of Systematic Reviews John Wiley and Sons Ltd; 2015

14 Jiang Q, Xiao S, Shu L, Huang X, Chen X, Hong H. Pituitary Apoplexy Leading to Cerebral Infarction: A Systematic Review. Eur Neurol 2020;83(02):121-130

15 Klein M, Koedel U, Pfefferkorn T, Zeller G, Woehrl B, Pfister HW. Arterial cerebrovascular complications in 94 adults with acute bacterial meningitis. Crit Care 2011;15(06):1-7

16 Banerjee C, Snelling B, Hanft S, Komotar RJ. Bilateral cerebral infarction in the setting of pituitary apoplexy: a case presentation and literature review. Pituitary 2015;18(03):352-358 